"This is the peer reviewed version of the following article: [Clegg, S.R., Cunha, M.P. \& Rego, A. 2016, 'Explaining Suicide in Organizations: Durkheim Revisited', Business and Society Review.], which has been published in final form at [http://onlinelibrary.wiley.com/doi/10.1111/basr.12092/abstract ]. This article may be used for non-commercial purposes in accordance with Wiley Terms and Conditions for Self-Archiving." 


\title{
EXPLAINING SUICIDE IN ORGANIZATIONS: \\ DURKHEIM REVISITED
}

\begin{abstract}
Drawing on Durkheim's concept of anomie, we address the under-explored phenomenon of anomic suicide in contemporary organizations, and discuss the consequences of solidarity for organizations and society. The relations of social solidarity to issues of identity and insecurity are explored through the cases of France Telecom/Orange and Foxconn. Remedial implications for organizing, considered as community building, are discussed. Durkheim wrote not only about anomic but also altruistic suicide. We will also analyze examples of this type of suicide. Some tentative suggestions are made for how to organize in order to minimize the incidence of suicidal violence in organizations.
\end{abstract}

Keywords: Violence, identity, anomie, suicide, Durkheim. 


\section{Introduction}

The contemporary news media regularly project overwhelmingly violent images into our homes and lives, including images of work-related violence (Flannery, 1996; Kelloway, Barling, \& Hurrell, 2006), such as workplace shooting and homicide (Fox \& Levin, 1994; Lankford, 2013), revenge (Jones, 2009), human trafficking (Chuang, 2006), and modern slavery (Crane, 2013). Some expressions of workplace violence, however, are less spectacular and more private, less other-directed and more self-directed, yet in no way less tragic. These cases assume symbolic value but do not find expression in collective action, ethics, or membership premised on alternate and oppositional values (Beale \& Mustchin, 2014). These include the recent suicidal waves at France Telecom/Orange and at Foxconn (Lucas, Kang, \& Li, 2013), which we use to reflect on our topic. They express an important but under-researched side of literal, rather than metaphorical organizational death, (see Bell, Tienari \& Hansson, 2014), which may be best understood through a reconsideration of the classical sociological work of Durkheim (see also Cullen, 2014).

In this paper we contribute to the organization and management literature by contributing to the "hugely under-researched" (Cullen, 2014, p. 42) topic of suicide as a work and organizational phenomenon. Doing such investigation is valuable, considering recent empirical evidence suggesting the upward trend of suicides in the workplace (Germain, 2014; Tiesman et al., in press). Despite the recent focus on positive approaches to management and organization (Cameron \& Spreitzer, 2012), several features and practices of workplace contexts that diminish the potential for human flourishing and that at the extreme provoke bursts of destructiveness, are still recurrent. For instance, socially unsustainable organizational environments (Pfeffer 2010, 2011) characterized by the 
poverty of human relating (Melé, 2012); the lack of integrative relational organizing (Carmeli \& Gittell, 2009; Gittell \& Douglass, 2012); the absence of a logic of care (Garvin, 2013); the creation of organizations as pure economic entities, as production functions devoid of some basic features of humanity that reduce resilience, and the presence of workplace stressors with perverse consequences for psychological and physical health (Goh, Pfeffer, \& Zenios 2015; Pfeffer, 2011; Tiesman et al., in press). Such practices, we suggest, can be partly explained by total institutional spaces that strip people of their individuality and human bonds of solidarity (Goffman, 1961; Lucas et al., 2013); in such circumstances a lack of solidarity results from changing disciplinary regimes that unsettle and disconnect organizational members from each other and from collective meaning.

We shall consider a pair of cases that can be linked, ethically, to a classical sociological discourse: the study of suicide by Emile Durkheim. The resonance of Durkheim's theory is apparent in a number of disparate contemporary cases: school shooters reject and affirm nothing other than existential despair and destruction; the committed unionist rejects the exploitative ethics of the employing organization while affirming those of the collective and solidarity; the young migrant worker's suicide rejects the ethics of an organization that exploits their membership. Societal phenomena at the extremes of organizing can shed light on major issues confronting organizations, ethics, and society. In particular, we will focus on how cases of too little solidarity in work organizations may lead to dysfunctional expressions of identity and pose important challenges for both policy makers and business managers, as work is a crucial inclusion mechanism. Creating organizations where solidarity is expressed in a healthy, functional way is, therefore, a social imperative that should have attracted the attention of business ethicists and organizational scholars. Such scholars, as moral 
philosophers and empirical observers of the everyday, should ask themselves how to construct the organizations that function as vehicles for the expression of appropriate bonds of solidarity.

What does it tell us about the organization and ethics of societies when people elect suicide as their ultimate career terminus? The recent interest in compassionate organizing (Dutton, Workman, \& Hardin, 2014; Simpson et al., 2013) should not lead us to ignore those cases marked by a lack of compassion, solidarity, and rich forms of intersubjective relationality (Gittell \& Douglass, 2012) as organizational outcomes. On the contrary, we should see compassionate organizing as an effective antidote against toxicity in workplaces, for the sake of the greater good. There is little more toxic than the voluntary extinguishment of life by young people. Peus (2011, p. 955) points out that organization scholars should be "asked to contribute to the question of how the organizations can alleviate human suffering and promote the greater good".

With the above questions in mind, we start by elaborating Durkheim's theory; second, we discuss the expression of suicidal violence in organizational settings, in terms of the category of anomie. Third, we discuss anomic suicide as an organizational phenomenon. We draw implications for understanding and managing organizations and for cultivating solidaritybased forms of organizational and societal ethics. We focus on the cases of Foxconn and France Telecom, two exemplars belonging to different industries, in different continents, which present different manifestations of suicide in the organizational context.

The article contributes to a literature that is still limited, and a topic that is too tragic to be ignored. Studying the occurrence of work-related suicide helps to understand some of the 
major dysfunctions of modern organizing. The contemporaneity of the topic notwithstanding, the best starting point to initiate this conceptual exploration still lies in Emile Durkheim's classical work, largely ignored by organizational theorists, even those interested in suicide (Cullen, 2014, p. 46).

\section{Durkheim's Suicide}

Durkheim's theory of social regulation and integration was established in Suicide (1897 [1997]). In this seminal work, Emile Durkheim constructed a sociological theory of suicide based on the macro-social effects of social regulation and integration on suicide rates. He examined suicide as a social phenomenon rather than an individual, psychological problem, wanting to demonstrate that even the most seemingly psychological of phenomena, such as suicide, could be explained as a social fact, i.e. sociologically. First, he examined the association between rates of confinement for mental illness and suicide rates and found no correlation. If there had been, then there would have been many more female suicides than male suicides because there were four times as many women as men confined in the European government statistics that he researched. Also, Jews would have had the highest rates of suicide instead of the lowest because they had the highest rates of psychological disorders amongst the different religions in his native France. Moreover, adolescents, who have the highest rates of psychological disorders, would be the age group that most frequently killed themselves albeit that suicide rates increased with age.

Having dispensed with psychological explanations, Durkheim argued it was the existence of certain social facts that explained variable suicide rates. The key social fact was what he called social solidarity - the degree to which individuals are integrated into social groupings 
through sharing common values and meanings, giving rise to densely connected and frequent interactions. It was the degree of social integration experienced that explains variable rates of suicide amongst different social categories of persons, according to Durkheim.

Durkheim outlined four types of suicide: altruistic, egoistic, fatalistic, and anomic, which can all occur in organizational contexts, as depicted in Figure 1. They were distinguished in terms of the degree of social regulation and integration. Social integration refers to social solidarity: those ties and bonds that integrate the person into the wider society. Where there is adequate integration there is an interaction between the individual and society, building individual feelings of solidarity and camaraderie, and binding people together through a network of mutual obligations and connections. A strongly integrated society "...holds the individual under its control, considers them at its service and thus forbids them to dispose willfully of themselves" (Durkheim, 1897 [1997], p. 209).

Figure 1 about here

Integration is typically a good thing; it builds social solidarity and belongingness. However, there can be too much of a good thing: where an individual is too strongly integrated into a social order, he/she can lose any sense of self-identity and come to value the interests of that order over and above their own life interests. Where these feelings of integration are over-developed, the individual may commit altruistic suicide. In such cases the person sacrifices themselves for the greater good of the social order whose bonds constitute their overwhelming sense of social solidarity. This is expressed in the case of terrorist attacks sometimes perpetrated against core institutions, including those that symbolize the world's 
capitalistic order. Just as, in Durkheim's reckoning, too much integration can, literally, be fatal, so can too little. An individual who is not integrated can experience loneliness and a sense of lack of greater purpose and commit egoistic suicide.

The other dimension, social regulation, refers to the social forces and norms that limit people's innate, insatiable desires. A society with too much regulation can constrain individuals too much and force them to commit fatalistic suicide. However, without regulation, Durkheim argues, our desires would be both uncontrollable and unsatisfied, leading to perpetual feelings of disappointment and powerlessness. In such cases individuals have unrealistic expectations and, when these are not met, where the person feels adrift in the norms that surround but do not embed them, they experience dissatisfaction and feelings of meaninglessness and hopelessness. Where this feeling of normlessness causes a person to take his or her life, Durkheim refers to this type of death as an anomic suicide. The category of relevance to the present discussion is that of anomic suicide, the case in which too little regulation combines with weak social integration. This category is more than a social fact of the past: it manifests in the present, as we discuss next, and unveils a contemporary malaise at the interface of business and society.

\section{Anomic suicide}

The probability of anomic suicide is raised considerably where a person is weakly socially integrated. Normally, strong, inescapable networks for solidarity exert powerful normative demands on the individual. However, if individuals are not strongly integrated into work and non-work networks, they will exist in a state of comparative normlessness - at least 
compared to peers with happy families and vital social networks amongst peer groups. They will be the classic loner, not integrated with their peers and remote from their families. ${ }^{1}$

In organizations, an equivalent process operates, with some companies severing social bonds and creating conditions for anomie, therefore giving rise to serious issues related to professional identity and personal sense of worth (Hodson, 1999). Issues of identity are important, as we learn from Durkheim. It is the lack of social confirmation and reinforcement of the identity of the individual's self-worth that leads to anomic suicide. Being neither strongly regulated by family nor integrated into other bonds of social solidarity, the disintegrated individual leads a life that is increasingly unbounded by the wider social norms and more and more bound up with fantasies of retribution for the humiliations of and to their identity that they experience. Self-actualization is sought not through networks of others as occurs in healthy organizations (e.g. Wagner \& Harter, 2006) but in the vengeance of the self, often wrapped up in a persona that is explicitly marginal in its presentation. The self builds barriers that isolate and distinguish it further through its

\footnotetext{
${ }^{1}$ Being poorly integrated, for whatever reasons of psychological or social maladaptation, troubled individuals are more likely to be the targets of phenomena such as workplace bullying (Rayner \& Cooper, 2006) or moral harassment (Claybourn, 2011). In turn, this will only exacerbate their psychological problems. The phenomenon is not exclusively experienced in business firms, of course, being even more publicly visible in other settings, such as schools. In such contexts it can take the form of behavior that will inevitably lead to the death of the protagonists - a form of suicide at the hands of others. For instance, Columbine shooters Eric Harris and Dylan Klebold had both been bullied for years. They complained to the principal of their school; however, many of their fellow classmates admitted that bullying was not stopped or discouraged sufficiently to make their lives any easier. The shooter at Virginia Tech was also bullied in school and had psychiatric problems that were not being effectively treated. The shooter at Jokela had posted a video called "Jokela high school massacre 11/7/2007" on YouTube prior to the shootings, which showed a picture of a building by a lake and photos of him holding a gun. Going by the username Sturmgeist89, he called himself a "social Darwinist" who would "eliminate all who I see unfit", sentiments strongly suggestive of a disturbed psyche as well as a high degree of social disintegration. It is significant that in the worst shootings to have occurred in Australia, the Port Arthur massacres, the perpetrator, Martin Bryant, who murdered 35 people, also saw himself as the victim. More often than not, these situations result in the death of the self, often after symbolic targets of dysfunction have been attacked and annihilated, materially or symbolically.
} 
beliefs and values - often expressed through social network sites - and conceives a project that ends in the death of the self.

\section{Methodological note}

Methodologically we interpret two case studies (Yin, 2003) with a Durkheimian lens. The case study responds to questions of how and why, and therefore seems suitable to the present investigation. The two cases were selected because of their unique combination of similarity and difference. The cases are similar in the sense that they both refer to suicide in organizations, but they reflected realities of different industries, different modes of ownership and governance, and even different continents. The two cases are also extreme in the sense that they offer a reality that may be a conceptual outlier. But extreme cases also offer a degree of conceptual clarity that may be absent from other, more common cases (Eisenhardt \& Graebner, 2007; Flyvbjerg, 2006). To explore our cases we approached them via a combination of indirect sources, mostly media reports and their academic interpretation in organization and management studies, business ethics and the sociology of organizations.

\section{The cases: Organization and anomic suicide in two organizations}

Suicide is a social fact, says Durkheim, with a macro-focus on national rates of suicide and an explanation couched in term of constructs of social solidarity. Yet, variation occurs not only at the national but also the organizational level, as two widely reported cases demonstrate.

The cases are Orange/France Telecom and the Chinese factories of the Taiwanese manufacturer Foxconn. Let us consider the French case first. 


\section{Orange/France Telecom}

Orange is the new name of the formerly state-owned France Telecom. France Telecom was privatized in 2004, sparking a major restructuring and the loss of scores of jobs, as new efficiency measures were introduced and the old public sector culture traduced. In 2006 an internal memo to directors from CEO Didier Lombard stated a strategic intent of cutting 22,000 jobs (Wilsher, 2014). As job-shedding efficiencies accumulated, the wave of suicides amongst employees became a matter of public concern. Thirty-five employees killed themselves between 2008 and 2009. Lombard suggested that suicide was a "fashion" at the company, an opinion that was strongly criticized for its insensitivity (and that reflects or explains a poor level of social integration within the company, one could argue).

In 2010 an official report by the works inspectorate blamed a climate of management harassment for psychologically weakening staff and causing the deterioration of their physical and mental health. In the wake of the report and mounting public pressure from the media, Lombard resigned as CEO in 2010, retaining the role of Chairman. In 2012, Lombard was accused of installing brutal management methods amounting to moral harassment and became the subject of a police investigation into the deaths. As a result of these attentions, the situation was seen to have improved. However, a second wave of suicides took place in the following years (Rousseau, 2015; Willsher, 2014). The company's Observatory for Stress and Forced Mobility, which monitors staff well-being and was established after the 2008/09, reported that the majority (eight) of the suicides (ten) occurred in the first months of 2014, were explicitly work-related, issuing a warning to management that as the remaining workforce became subject to improved efficiency measures for greater productivity, including compulsory relocations, further site closures 
and job losses creating increased competition between workers, morale was going down fast.

Given the traditional economic model in France, in which employees could in principle expect to work for almost all their lives in very large state-run companies, this change of psychological contract through privatization can be extremely demanding. "Work normally protects people from thinking about suicide as it's normally those whose are unemployed or living in poverty who are most at risk, but in recent years, in some cases work has actually been a cause to push people to take such extreme action", said Jean-Claude Delgenes, the director of Technologia, a company which focuses on safety concerns for workers. The issue is one of too much solidarity focused on work place relations that metamorphoses into too little solidarity. As Delgenes (McPartland, 2014) sees it,

A lot of people, perhaps some who have worked for state-run companies, often find themselves lost with the pace of change. They cannot find their feet and are being asked to do different jobs, which they may never have been trained for and cannot cope with. In Anglo countries people don't have the same relationship with work. They change jobs more often and try new careers but in France people really identify themselves with a job, especially if they have trained for it and it's hard for them to change, especially in a time of high unemployment.

Later, this analysis was confirmed by the replacement CEO for Lombard, Stéphane Richard:

Even though the firm's suicide rate is in line with the national average, France Telecom says that it was partly to blame. Because of the group's former status as part of government, 66,000 or $65 \%$ of its employees are classed as civil servants, 
with guaranteed tenure. Unable to fire them, France Telecom instead subjected them to a system called "Time to Move", in which they were obliged to change offices and jobs abruptly every few years ... "The former management needed to change the nature of peoples' jobs due to technological change and increased competition," says Mr Richard, "but the company underestimated the consequences." For the first time in 15 years, he has promised, France Telecom will expand its workforce. Job and office moves will become voluntary, and up to $30 \%$ of the variable pay of the firm's top 1,100 managers will be tied to their "social" performance. Other measures include making France Telecom's numerous offices more pleasant: the company will renovate 800 of its buildings and create 270 new "conviviality spaces" for employees. (The Economist, 2010)

Civil servants with guaranteed tenure enjoy considerable opportunity to develop social solidarity. One of the ways to change such an organization when it is privatized is to do what Lombard did: to force through changes, to brutally introduce a new culture. However, there can be managerial consequences that are unexpected at the time the brave new world of change is commissioned. On 4 July 2012 Lombard was indicted for overseeing a campaign and culture of moral harassment of employees, allegedly driving over 30 staff under his watch to suicide. Lombard's Deputy and his Human Relations Manager were also accused. If nothing else, this should stand as a cautionary note for those managers who decide to follow a course of action in which they use the claims of managerial prerogative to force through radical changes that destroy the normative fabric of an organization in the name of efficiency (Jones [2012] provides a compelling narrative of the unfolding events attendant on the privatization of France Telecom and its search for greater efficiencies through 
authorized harassment, forced redeployments and management by fear, intimidation and coercion).

Foxconn

The explanation for the suicide wave at Foxconn seems to have some similarities with the events at Orange/France Telecom but also some significant differences. Between January and November 2010, eighteen Foxconn employees attempted suicide with fourteen deaths. All the suicides were aged between 18 and 28 , and most died by jumping from the dormitory. The suicides drew media attention to employment practices at Foxconn, a large subcontract manufacturer working for many household names, of which Apple is the best known. In the wake of these suicides, a research team from twenty Chinese universities produced a report on Foxconn in which its Shenzhen plant was described as a "labour camp" (Tam, 2010). A culture of long working hours as well as discrimination of Mainland Chinese workers by their Taiwanese supervisory co-workers produced a lack of collaborative working relationships (Moore, 2010). The Foxconn workers, typically, are young people, drawn from the peasantry from China's vast interior, who have migrated to the coastal free trade zones in search of work. At Foxconn, as is the common practice in such installations, they live in company dormitories in barrack-like conditions in close proximity with the many other strangers who work there.

Foxconn's response to unfavorable media coverage of these suicides was to install suicide netting, ask workers to sign no-suicide pledges as well as a legally binding document guaranteeing that they and their descendants would not sue the company as a result of unexpected death, self-injury or suicide (Malone \& Jones, 2010). The suicide rate at Foxconn 
was not high in terms of the overall Chinese suicide rate but was striking in its concentration in a youthful population rather than the elderly or those women left behind in villages by their absent husbands working in the special economic zones.

Two factors, in particular, seemed to be in play. One was the total institutional nature of life in Foxconn (Goffman, 1961; Lucas et al., 2013). The working week was long, often as a result of the young employees working extra shifts in order to be able to remit more money to the family in the interior, meaning that there was little downtime other than in the dormitory, due to exhaustion. The other factor seems to be the authoritarian management practices that were allowed to flourish within such total institutional environment.

We know about the management practices through interviews conducted with one survivor of a suicide attempt at Foxconn. At around 8am on 17 March 2010, 17-year-old Tian Yu threw herself from the fourth floor of her factory dormitory in Shenzhen. For the past month, the teenager had been working on the assembly line churning out parts for iPhones and iPads. Tian Yu did not succeed in killing herself: emerging from a 12-day coma, she was left with fractures to her spine and hips and paralyzed from the waist down. Jenny Chan and Sacom, a Hong Kong-based group of rights campaigners, interviewed Yu over three years. From her hospital recuperation in Shenzhen to her return to her family's village, Yu was extensively interviewed (Chan, 2013). Yu's narrative is her story but it could be replicated hundreds and thousands of times because in terms of the journey that bought her to Shenzhen is a similar story to that of most of Foxconn's employees. She worked more than 12 hours each day, six days a week, with no training. She was compelled to attend early work meetings for no pay, and to skip meals to do overtime. Toilet breaks were restricted; mistakes led to humiliating public dressing-downs. 
In her first month, Yu had to work two seven-day weeks back to back being too exhausted to do anything but sleep when not working. She was swapped between day and night shifts and kept in an eight-person dormitory where she barely knew the names of her fellow sleepers. She was stranded in a city far from her family, unable to make friends or even get a decent night's sleep. When she didn't get paid for her month's labor for reasons that were unclear to her, she jumped out of the dormitory window in desperation. As Chakrabortty (2013) argues, Yu's experience flies in the face of Foxconn's own codes, let alone Apple's, whose iPhones she was producing. Apple drives a hard supply chain bargain on Foxconn such that it makes very slim margins on the goods it produces; its profit is equivalent to whatever surplus value it can squeeze from the million or so employees it houses in its factories and dormitories. The basic method for extracting this surplus value is through authoritarian management and exhausting labor (Chan, 2013). The effects on young people, isolated from their families, hundreds of miles from home, thrown into close proximity with a mass of strangers is, not surprisingly, often traumatic. They do not feel any sense of belonging and their work provides no sense of social solidarity because of its atomization, intensity, and the estrangement it offers.

\section{Discussion and implications}

Violence, such as that contained in the episodes we studied, make it mandatory to develop a better understanding of the relationship between organization and self-directed, suicidal forms of violence. We suggested that Durkheim's work is still a good place to initiate this study in contemporary organizational settings. From Durkheim we now draw a number of lessons on how to counter anomic suicide. We have discussed organizationally induced anomie and suicide. In France Telecom the past offered a great deal of social solidarity; 
workers were employed for life, the public sector employer looked after their needs and they were accustomed to a predictable way of working. The privatization changed these conditions dramatically: new disciplines of more intensified and competitive work regimes were introduced; competitive relations were favored where previously solidarity relations had prevailed; staff became subject to large scale redundancies. A previously highly normatively predictable and socially regulated environment changed dramatically; the old norms no longer applied as new managerial norms were introduced. For some employees, comfortable in the accustomed ways of working, these changes rocked the foundations of their normative universe and for some of these the anomie attendant on the radical changes seemed to beckon suicide as the only solution.

In Foxconn, the workers never developed much in the way of social solidarity at all. Their social fragmentation and isolation, coming from thousands of different and isolated villages in the interior, subject to factory and dormitory disciplines that were imposed on these young peasants in an effort to make them into proletarians, was not conducive to the creation of a solidaristic work ethic, such as France Telecom's old public sector culture provided. They came isolated and alienated into a culture in which anomie was normal, intensified by the total institutional characteristics of the plant and dormitory life, and the alienation that they experienced as a result of the contempt with which Taiwanese supervisors had for these ignorant peasants that they bullied and harassed at work. Anomie was normal and for some young people became intolerable.

There was little if any exercise of surveillance and care, no skilled psychological counselling to which workers could be referred and monitored, nor contact with or advice to distant families. Apple and other primary contractors were disinterested in how their profits were 
made down in the supply chain; they had formal codes as insurance policies that they could use as fig leaves to cover their discomfiture if investigative reporting caused embarrassment. However, there was no intervention to create more relational and inclusive forms of organizing and leadership, providing training and direction, in the sub-contractor. Such forms of emphasis on stressing the importance of organizational inclusion would have acted as a powerful antidote against societal exclusion and might have saved lives.

\section{Durkheim and altruistic suicide}

Anomic suicide is clearly a current problem, as we have illustrated by using Durkheim's theorizing to explain one manifestation of the phenomenon of organizational violence. But Durkheim's work opens additional conceptual possibilities at the boundary between business and society. In this section we briefly explore one possibility that seems particularly urgent: altruistic suicide. It is not merely the marginally integrated self that is dangerous, suggests Durkheim. It is also those selves that are too tightly integrated and regulated by bonds of social solidarity; who suffer from a surfeit of identity with others, rather than a deficit. Too much bonding is a "deadly virtue" (North, 2011) and, thus, can be as negative as too little. Faced with a community that cannot imagine a place in its midst for specific others not like themselves in ways that are taken to be significant, it may be hardly surprising if those specific and stigmatized others seek to imagine an antithetical community that excludes all those perceived as stigmatizing.

These are issues that many immigrant communities have to deal with. The matter is especially important in societies that are getting more globalized and culturally diverse. For any diasporic community, the central issue is always one of cultural and professional 
integration, a "two-sided process of immigrants" adjustment to a new society without loss of what they consider essential to their identity or self-definition, including the sense of their religion or ethnicity and, simultaneously, of the adoptive society's accommodation of them (McGown, 1999, p. 43). The notion of difference indexed by the conceptions of ethnicity is usually thought of in terms of a continuum that stretches from a primordial, internal concept to one that is external and structural.

Primordially, it is the attachments and relations that one carries with one that define identity; structurally, it is the boundaries determined by the larger society rather than the life-world that the communities construct that defines them. Externally, Isajaw (1979, p. 2122) defines an ethnic group as an "involuntary group of people who share the same culture or to descendants of such people who identify themselves and/or are identified by others as belonging to the same involuntary social group". In many developed societies, especially where the Muslim population is concerned, external and internal definitions coincide.

The act of renunciation is constructed as an altruistic suicide that doubles as an act of homicide. The person kills themselves both in order to express their love and commitment to an ethic and ideals that transcend them in their imagined community and in order to show how deeply integrated into those alternative ethics and ideals they are: the renunciation is simultaneously an act of commitment to the ethic and the future utopia it will create. What makes them want to die is a sense of total and alternative ethical social integration that functions as the source of their social solidarity, as well as a total estrangement from the norms of the society whose members they will also dispatch with their act. 
The process is not entirely psychological: the role of the host state, opportunities for professional integration, actions of law enforcement agencies, the expression of opinions by populist media and politicians, the campaigns of international relations and popular struggles elsewhere, can all help shape the process. ${ }^{2}$ In the absence of some of those social bonds some young people will be drawn to a dystopian view of reality expressed through organizations that make the search for utopia a concrete project (Clegg, Cunha, \& Rego, 2012). Exploring the role of work and organizations in the success or failure of integration seems an important topic for organizational analysis. Societal integration supported by professional bonds and a relational ethics oriented towards organizational sustainability latu sensu (Pfeffer, 2010; Verbos \& Humphries, 2015) may, from a Durkheimian perspective, constitute a powerful antidote against altruistic suicide.

Implications for practice

The cases offer a number of implications for practice. We explore five, influenced by positive organization scholarship, i.e. on the basis of the assumption that organizations should pursue change that is positive and aligned with the greater good (Hanson, 2014; Peus, 2011). First, organizations should behave themselves as human communities of work (Cunha, Rego \& Vaccaro, 2019; Mintzberg, 2009; Pfeffer, 2006). When community and camaraderie links are destroyed, and when support and care are not communicated, organizations become indifferent production machines (e.g. Kets de Vries, 2001; Rego \& Cunha, 2012). Their contribution to the health and wellbeing of their members is negative

\footnotetext{
${ }^{2}$ For instance, politicians can escalate danger through promoting their short-term interests in mobilizing fear for electoral advantage: see http://www.smh.com.au/federal-politics/political-news/counterterrorism-adviserabbotts-is-death-cult-label-is-counterproductive-20150511-ggyl4i.html
} 
and their social costs are externalized to society (Goh et al., 2015; Pfeffer, 2010). It is worth noting that extreme cautiousness must be adopted when interpreting community statements of companies without testing the respective adherence to reality. This need is clear when one reads Foxconn's (2010) Corporate Social \& Environmental Responsibility annual report, which includes the word "love" 13 times. Consider the following sample (p. 50):

In 2010, Foxconn IE Academy and the Shenzhen Labor Union jointly hosted a total of 90 workshops with more than 8,700 attendees to improve employees' personal qualities and abilities. In addition, Foxconn set up various speech and debate competition shows on the topic of 'I love the company, the company loves me', and a happy mothers' forum (p. 23). (...) In 2010, Foxconn organized 12 major volunteer programs and more than 200 major and midsize activities to 'help the weak and the disabled, give love and support, and promote sanitation'. Foxconn's Volunteer Team encouraged volunteers to make a difference by way of numerous forms of charitable functions. In 2011, Foxconn intends to initiate a 'Foxconn Volunteer Network' to bring hope and love to those in crisis and to work together for a better society.

Second, several forms of institutional work may be pursued to avoid destructive organizing. Sensible temporal institutional work (Grandqvist \& Gustafsson, forthcoming) is necessary to create adequate rhythms of work and change. Excessive pace can be destructive and perceived as disrespectful (Carmeli et al., 2015). Positive institutional work (Nilsson, forthcoming) is also critical to promote organizational cultures of care and mutual support (Barsade \& O'Neill, 2014). Mutual support is also required to construct organizational 
resilience (Beunza \& Stark, 2003) and high quality connections (Dutton, 2014). Third, stimulating and training leaders in the creation of psychologically safe environments is a path towards not only collective learning and performance but also solidarity: in psychologically safe organizations, an individual's failure or weakness is a collective failure or weakness, and individuals feel safe to share their vulnerabilities with coworkers (or co religionists) without incurring in risk (Edmondson, 1999; Edmondson \& Lei, 2014). In psychologically safe climates, individuals are also more likely to speak up and ring the alarms against unhealthy management and organizational practices.

At a more macro level, public authorities and NGOs can examine, diagnose and discourage severe signs of dangerous management practice. These investigations should not be enacted or perceived as intrusions in managerial freedom but as responses to personal grave danger, such as that revealed by suicidal cases. The consequences can be considered both in terms of the protection of workers and the control of mounting healthcare costs. The identification of acceptable working conditions can also create a stimulus for fair competition in increasingly globalized industries. If competition is designed to improve the world, then it must be fair. The inhuman conditions with which some organizations confront their vulnerable workers gives them an unfair advantage and limits the dignity of workers, especially in some parts of the world, including China, a workers' state.

On the other hand, as our discussion reveals, some radical management measures following privatization reveal dysfunctions that can be prevented before privatization. Again, one does have to be against managerial freedom to consider that some management practices are closer to moral harassment than they are to good management. The transitioning to privatization can thus be represented as a co-responsibility of the seller rather than a one- 
off episode. Distinguishing managerial fiat and workplace harassment, may facilitate the prevention of abuse. The enactment of legislation such as the UK's "Duty of Care" (see Germain, 2014) is another possibility.

Finally, in terms of business organizations contractors should be careful in contracting suppliers who meet not only economic and environmental criteria, but also social sustainability metrics (Amini \& Bienstock, 2014; Pfeffer, 2010, 2011). In the absence of this consideration, competitiveness and financial goals may become the single goal of some suppliers, with no regard for basic human rights. At the global level, multinational companies must cooperate to build and adopt regulatory procedures in pursuing social sustainable practices that some national authorities and bodies are not able to enact and implement (Scherer \& Palazzo, 2011). This endeavor represents one of the most relevant practices that companies can adopt as a "political" approach to corporate social responsibility (Scherer \& Palazzo, 2007, 2011). As Scherer and Palazzo (2011, p. 913) argued "While in principle it is possible to translate the responsibility of a corporation for its direct suppliers into the legal logic of a contractual relationship in the sense of agency theory and the theory of the firm (Jensen and Meckling, 1976; Sundaram and Inkpen, 2004), for social and environmental problems further up the supply chain the liability concept of responsibility no longer holds". Otherwise, corporations will suffer significant losses in terms of "moral legitimacy" (Scherer \& Palazzo, 2011).

Durkheim's theorizing opens, in summary, important possibilities for studying two forms of violence at the interface between organization and society: anomic and altruistic suicide. In our perspective, organizational researchers have insufficiently addressed these two topics. With this paper we sought to call attention to them and to invite more research on them. 
Empirical tests of the previous topics are now necessary to explore the value of our theoretical propositions.

\section{Conclusion}

We used Durkheim's (1897) theory of social regulation and integration to discuss the phenomenon of anomic suicide, as well as its potential for future research on altruistic suicide. We specifically considered the influence of marginalization of people in organizations as a major issue with implications for the leadership of business firms. Organizations can be viewed as communities in relation with other communities. The bonds of solidarity connecting these communitarian spaces help to explain the problem of organizationally related violence. Researchers need, therefore, to study identity as a complex, multilevel, overlapping and sometimes contradictory process. The way these communities are represented influences their functioning via the relational choices of their members.

Episodes of suicide with anomic features are radical signs of major societal problems. Political and business leaders should thus be alert to their causes, processes and consequences. The extremism of the cases highlighted here should be taken as indicative of the malaise incubating in different societies. Such a malaise has an organizational component and needs to be tackled as an organizational issue by management scholars.

Suicidal waves of young workers at Foxconn and France Telecom/Orange are indicators of a problem that has received insufficient attention from the business ethics community. We departed from Durkheim's classical work to reflect about challenges resulting from such self-inflicted violence. The ethics literature has been ill equipped to deal with this issue. We 
sought to bring these issues to scholarly attention and to call for more research on how organizations can participate in the management of regulation and integration in ways that counter both the lack and the excess of solidarity. That work can kill the will to live is a fundamental ethical problem; it is time that management scholars attended to it as such.

\section{References}

Amini, M. \& Bienstock. C. C. (2014). Corporate sustainability: an integrative definition and framework to evaluate corporate practice and guide academic research. Journal of Cleaner Production, 76, 12-19.

Barsade, S. \& O'Neill, O. (2014). What's love got to do with it? A longitudinal study of the culture of companionate love and employee and client outcomes in the long term care setting. Administrative Science Quarterly, 59(4), 551-598.

Beale, D. \& Mustchin, D. (2014). The bitter recent history of employee involvement at Royal Mail: An aggressive management agenda versus resilient workplace unionism Economic and Industrial Democracy 35: 289-308

Bearman, P. (1991). The social structure of suicide. Sociological Forum, 6, 501-24.

Bell, E., Tienari, J. \& Hansson, M. (2014). Organizational death. Culture and Organization, 20(1), 1-6.

Beunza, D. \& Stark, D. (2003). The organization of responsiveness: Innovation and recovery in the trading rooms of Lower Manhattan. Socio-Economic Review, 1, 135-164.

Cameron, K. S., \& Spreitzer, G. M. (2012). The Oxford handbook of positive organizational scholarship. New York: Oxford University Press. 
Carmeli, A., Dutton, J. E., Hardin, A. E. (2015). Respect as an engine for new ideas: Linking respectful engagement, relational information processing and creativity among employees and team. Human Relations, forthcoming.

Carmeli, A., \& Gittell, J. (2009). High-quality relationships, psychological safety, and learning from failures in work organizations. Journal of Organizational Behavior, 30(6), 709729.

Chakrabortty, A. (2013). The woman who nearly died making your iPad, The Guardian, 6 August 2013, accessed at

Chan, J. (2013). A suicide survivor: The life of a Chinese worker. New Technology, Work and Employment, 28(2), 84-99.

Chuang, J. (2006). Beyond a snapshot: Preventing human trafficking in the global economy." Indiana Journal of Global Legal Studies 13(1), 137-163.

Claybourn, M. (2011). Relationships between moral disengagement, work characteristics and workplace harassment. Journal of Business Ethics, 100(2), 283-301.

Clegg, S., Cunha, M.P. \& Rego, A. (2012). The theory and practice of utopia in a total institution: The pineapple panopticon. Organization Studies, 33(12), 1735-1757.

Cohen-Almagor, R. \& Haleva-Amir, S. (2008). Bloody Wednesday in Dawson College - The story of Kimveer Gill, or why should we monitor certain websites to prevent murder. Studies in Law and Technology, 2(3): http://www.bepress.com/selt/vol2/iss3/art1/

Crane, A. (2013). Modern slavery as a management practice: Exploring the conditions and capabilities for human exploitation. Academy of Management Review, 38(1), 49-69.

Cullen, J. (2014). Towards an organizational suicidology. Culture and Organization, 20(1), 4052. 
Cunha, M.P., Rego, A. \& Vaccaro, A. (2014). Organizations as human communities and internal markets: Searching for duality. Journal of Business Ethics, 120(4), 441-455.

Durkheim, E. (1897). Suicide. Glencoe: The Free Press (reprinted 1997).

Dutton, J. E. (2014). Build high-quality connections In J.E. Dutton and G.M. Spreitzer (Eds.): How to be a Positive Leader. San Francisco: Berrett-Koehler, 11-21.

Dutton, J. E., Workman, K. \& Hardin, A. E. (2014). Compassion at work. Annual Review of Organizational Psychology and Organizational Behavior, 1, 277-304.

Edmonson, A. (1999). Psychological safety and learning behavior in work teams. Administrative Science Quarterly, 44, 350-383.

Edmondson, A. C. \& Lei, Z. (2014). Psychological safety: The history, renaissance, and future of an interpersonal construct. Annual Review of Organizational Psychology and Organizational Behavior, 1, 23-43.

Eisenberger, R., Karagonlar, G., Stinglhamber, F., Neves, P., Becker, T.E., Gonzalez-Morales, M.G., \& Steiger-Mueller, M. (2010). Leader-member exchange and affective organizational commitment: The contribution of supervisor's organizational embodiment. Journal of Applied Psychology, 95(6), 1085-1103.

Eisenhardt, K.M. \& Graebner, M. (2007). Theory building from cases: Opportunities and challenges. Academy of Management Journal, 50, 25-32.

Flannery, R.B. (1996). Violence in the workplace, 1970-1995: A review of the literature. Aggression and Violent Behavior, 1(1), 57-68.

Flyvbjerg, B. (2006). Five mis-understandings about case study research. Qualitative Inquiry, 12(2), 219-245.

Fox, J.A. \& Levin, J. (1994). Firing back: The growing threat of workplace homicide. Annals AAPSS, November, 16-30. 
Foxconn Technology Group (2010). Corporate social and environmental responsibility annual report. Retrieved October 14, 2014, from http://ser.foxconn.com/downloadAttachment/8abe98dc3c5f940a013c84e1ad3d0249 /2010+Foxconn+CSER+Annual+Report.pdf

Garvin, D. A. (2013). How Google sold its engineers on management. Harvard Business Review, 91(12), 74-82.

Germain, M.L. (2014). Work-related suicide: An analysis of US Government reports and recommendations for human resources. Employee Relations, 36(2), 148-164.

Gittell, J.H. \& Douglass, A. (2012). Relational bureaucracy: Structuring reciprocal relationships into roles. Academy of Management Review, 37(4), 709-733.

Goffman, E. (1961). Asylums. Harmondsworth: Penguin.

Goh, J., Pfeffer, J. \& Zenios, S. (2015). The relationship between workplace stressors and mortality and heath costs in the United States. Management Science.

Grandqvist, N. \& Gustafsson, R. (forthcoming). Temporal institutional work. Academy of Management Journal.

Hanson, K.O. (2014). Six unavoidable ethical dilemmas every professional faces. Business and Society Review, 119(4), 537-552.

Hodson, R. (1999). Organizational anomie and worker consent. Work and Occupations, 26(3), 292-323.

http://www.theguardian.com/commentisfree/2013/aug/05/woman-nearly-died-makingipad on 27.05.14

Isajiw, W.W. (1979). Definitions of ethnicity. Toronto: Multicultural History Society of Ontario. 
Jones, D. A. (2009). Getting even with one's supervisor and one's organization: relationships among types of injustice, desires for revenge, and counterproductive work behaviors." Journal of Organizational Behavior, 30(4), 525-542.

Jones, E. (2012). The rich and the dead at France Telecom: The privatization from hell, Counterpunch, July 2012, 23 accessed at http://www.counterpunch.org/2012/07/23/the-privatization-from-hell/ on 27.05.14

Kelloway, E.K., Barling, J. \& Hurrell, J.J. (Eds.)(2006). Handbook of workplace violence. Thousand Oaks, CA: Sage.

Kets de Vries, M. F. R. (2001). Creating authentizotic organizations: Well-functioning individuals in vibrant companies. Human Relations 54(1), 101-111.

Lankford, A. (2013). A comparative analysis of suicide terrorists and rampage, workplace, and school shooters in the United States from 1990 to 2010. Homicide Studies, 17(3), 255-274.

Lucas, K., Kang, D., \& Li, Z. (2013). Workplace dignity in a total institution: Examining the experiences of Foxconn's migrant workforce. Journal of Business Ethics, 114, 91-106.

Malone, A. \& Jones, R. (2010). Revealed: Inside the Chinese suicide sweatshop where workers toil in 34-hour shifts to make your iPod". Daily Mail 6 December 2010, accessed at http://www.dailymail.co.uk/news/article-1285980/Revealed-InsideChinese-suicide-sweatshop-workers-toil-34-hour-shifts-make-iPod.html, on 27.05.14.

Melé, D. (2012). The firm as a "community of persons": A pillar of humanistic business ethos. Journal of Business Ethics, 106(1), 89-101.

McGown, B.R. (1999). Muslims in the diaspora: the Somali communities of London and Toronto. Toronto: University of Toronto Press. 
McPartland, B. (2013) Why France has such a high rate of suicides, The Local, 10 September 2013, accessed at http://www.thelocal.fr/20130910/why-france-has-such-a-highsuicide-rate, on 27.05 .14

Mintzberg, H. (2009). Rebuilding companies as communities. Harvard Business Review JulyAugust, 140-143.

Moore, M. (2010). What has triggered the suicide cluster at Foxconn? The Daily Telegraph, May $16 \quad 2010, \quad$ accessed at http://blogs.telegraph.co.uk/news/malcolmmoore/100039883/what-has-triggeredthe-suicide-cluster-at-foxconn/on 27.05.14

Nilsson, W. (forthcoming). Positive institutional work: Exploring institutional work through the lens of positive organizational scholarship. Academy of Management Review.

North, S. (2011). Deadly virtues: Inner-worldly asceticism and karôshi in Japan. Current Sociology, 59(2), 146-159.

Pape, R. (2006). Dying to win: The strategic logic of suicide terrorism. New York: Random House.

Peus, C. (2011). Money over man versus caring and compassion? Challenges for today's organizations and their leaders. Journal of Organizational Behavior, 32(7), 955-960.

Pfeffer, J. (2006). Working Alone: What ever happened to the idea of organizations as communities. In E.E. Lawler and J.O'Toole (Eds.), America at work: Choices and challenges (pp. 3-21). New York: Palgrave McMillan.

Pfeffer, J. (2010). Building sustainable organizations: The human factor. Academy of Management Perspectives, 24(1), 34-45.

Pfeffer, J. (2011). Could we manage not to damage people's health? Harvard Business Review, November, 42. 
Rayner, C. \& Cooper, C.L. (2006). Worplace bullying. In Kelloway, E.K., Barling, J. \& Hurrell, J.J. (Eds.). Handbook of workplace violence (pp.121-145). Thousand Oaks, CA: Sage.

Rego, A. \& Cunha, M.P. (2012). They need to be different, they feel happier in authentizotic climates. Journal of Happiness Studies, 13(4), 701-727.

Rousseau, C. (2015). Les suicides continuent chez l'ex-France Télécom. L'Humanité, 16 Avril. Accessed at http://www.humanite.fr/les-suicides-continuent-chez-lex-france-telecom571478, on May 14, 2015.

Schneider, K.T., Swan, S. \& Fitzgerald, L.F. (1997). Job-related and psychological effects of sexual harassment in the workplace: Evidence from two organizations. Journal of Applied Psychology, 82(3), 401-415.

Scherer, A. G. \& Palazzo, G. (2007). Toward a political conception of corporate responsibility: Business and society seen from a Habermasian perspective. Academy of Management Review, 22(4), 1096-1120.

Scherer, A. G. \& Palazzo, G. (2011). The new political role of business in a globalized world: A review of a new perspective on CSR and its implications for the firm, governance, and democracy. Journal of Management Studies, 48(4), 899-931.

Simpson, A., Clegg, S. \& Cunha, M.P. (2013). Expressing compassion in the face of crisis: Organizational practices in the aftermath of the Brisbane floods of 2011. Journal of Contingencies and Crisis Management, 21(2), 115-124.

Tam, F. (2010) Foxconn factories are labour camps: Report. South China Morning Post, 11 October 2010, accessed at http://www.scmp.com/article/727143/foxconn-factoriesare-labour-camps-report, on 27.05.14 
The Economist (2010) Doctor or Decorator? The Economist. April 8, 2010, accessed at http://www.economist.com/node/15872735?zid=292\&ah=165a5788fdb0726c01b137 4d8e1ea285 on 27.05 .14

Tiesman, H. M., Konda, S., Hartley, D., Menéndez, C. C., Ridenour, M., \& Hendricks, S. (in press). Suicide in U.S workplaces, 2003-2010: A comparison with non-workplace suicides. American Journal of Preventive Medicine.

Vandekerkhove, W. \& Commers, M.S.R. (2003). Downwards workplace mobbing: A sign of the times? Journal of Business Ethics, 45(1), 41-50.

Verbos, A. \& Humphries, M. (2015). Amplifying a relational ethic: A contribution to PRME praxis. Business and Society Review, 120, (1), 23-56.

Wagner, R. \& Harter, J.K. (2006). 12: The elements of great managing. New York: The Gallup Press.

Wainwright, R. (2009). Mass murderer wanted someone to stop him. Sydney Morning Herald, April 26. http://www.smh.com.au/national/mass-murderer-wanted-someoneto-stop-him-20090425-aiqc.html

Willis, P. (1977) Learning to labour: How working class kids get working class jobs. Farnborough, Hants: Saxon House.

Wilsher, K. (2014) Orange France investigates second wave of suicides among staff. The Guardian, March 20, 2014, accessed at http://www.theguardian.com/business/2014/mar/19/orange-france-investigatessecond-wave-suicides, on 27.05.14

Yin, R.K. (2003). Case study research. Design and methods. Thousand Oaks: Sage. 
Figure 1

Altruistic and anomic violence in society and organization: A framework

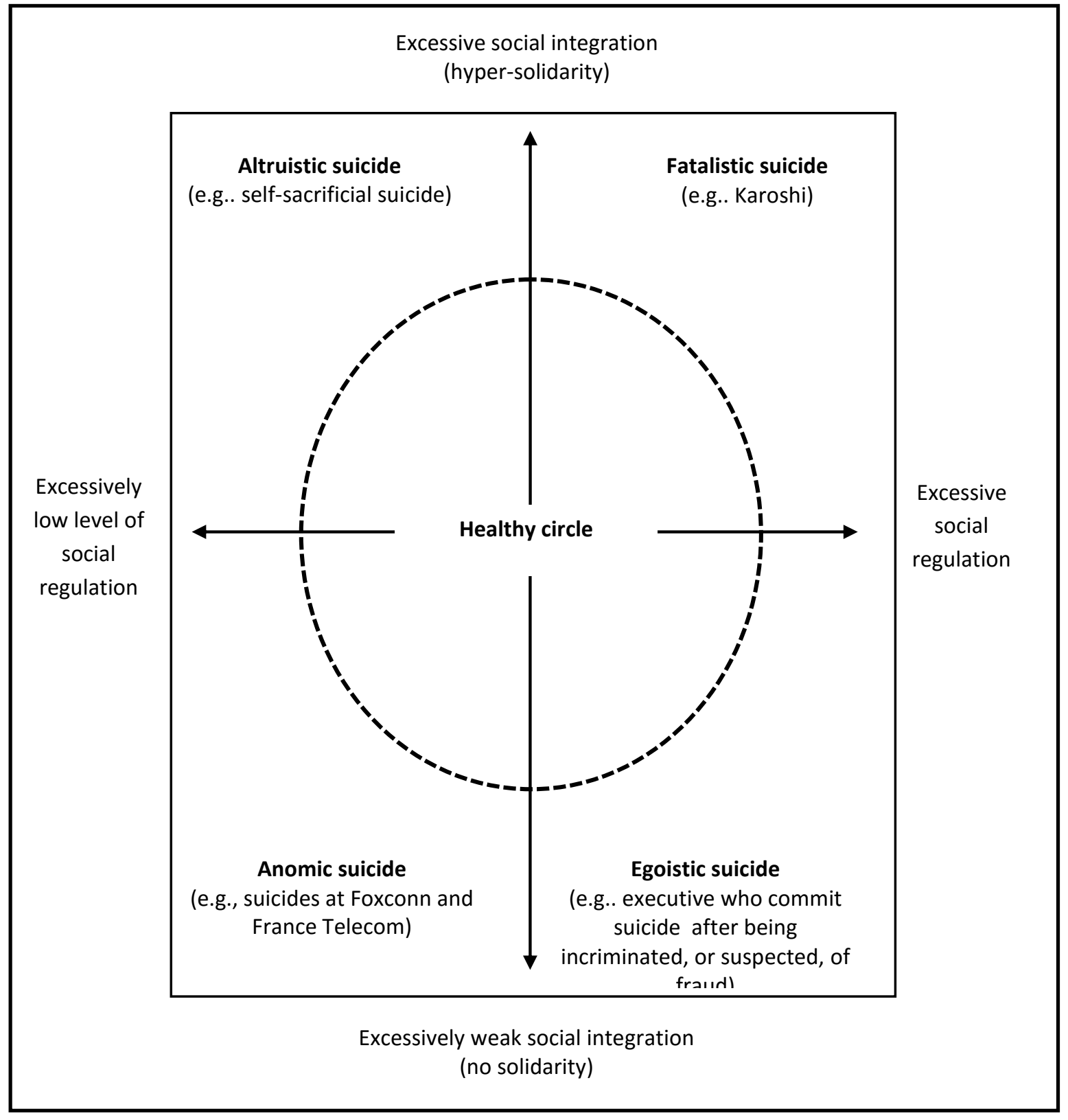

